\title{
Catalyst-free synthesis of 4-acyl-NH-1,2,3-triazoles by water-mediated cycloaddition reactions of enaminones and tosyl azide
}

\author{
Lu Yang ${ }^{1}$, Yuwei Wu ${ }^{1}$, Yiming Yang ${ }^{1}$, Chengping Wen ${ }^{* 2}$ and Jie-Ping Wan ${ }^{* 1}$
}

\author{
Full Research Paper \\ Address: \\ ${ }^{1}$ College of Chemistry and Chemical Engineering, Jiangxi Normal \\ University, Nanchang 330022, P. R. China and ${ }^{2}$ College of Basic \\ Medical Sciences, Zhejiang Chinese Medical University, Hangzhou \\ 310053, P. R. China \\ Email: \\ Chengping Wen* - cpwen.zcmu@yahoo.com; Jie-Ping Wan* - \\ wanjieping@jxnu.edu.cn \\ * Corresponding author \\ Keywords: \\ additive-free; catalyst-free; cycloaddition; enaminones; on water; \\ 1,2,3-triazole
}

\author{
Beilstein J. Org. Chem. 2018, 14, 2348-2353. \\ doi:10.3762/bjoc. 14.210 \\ Received: 03 July 2018 \\ Accepted: 22 August 2018 \\ Published: 07 September 2018 \\ Associate Editor: L. Vaccaro \\ (C) 2018 Yang et al.; licensee Beilstein-Institut. \\ License and terms: see end of document.
}

\begin{abstract}
The synthesis of 4-acyl- $\mathrm{NH}$-1,2,3-triazoles has been accomplished with high efficiency through the cycloaddition reactions between $\mathrm{N}, \mathrm{N}$-dimethylenaminones and tosyl azide. This method is featured with extraordinary sustainability by employing water as the sole medium, free of any catalyst or additive, authentically mild conditions ( $40{ }^{\circ} \mathrm{C}$ stirring) as well as practical scalability.
\end{abstract}

\section{Introduction}

Discovering sustainable chemical syntheses constitutes one central issue of modern organic chemistry. A large number of strategies and concepts promoting sustainable syntheses have been conceived over the past decades. Methods employing water as reaction medium are amongst the most promising ones by avoiding the application of volatile organic solvents during the reaction process [1-3]. Besides acting as a safer and environmentally benign alternative to organic solvents, on water reactions are known for their accelerated reaction rates and improved synthetic selectivity [4-6]. Being inspired by these commonly recognized green features, flourishing advances in the research of water-mediated or promoted organic syntheses, including those reactions involving valuable $\mathrm{C}-\mathrm{C}$ [7-11], C-heteroatom [12-16], heteroatom-heteroatom [17,18] bond formation as well as divergent cascade reactions [19-23], are presently taking place to guide the progress of sustainable organic synthesis.

1,2,3-Triazole is a heterocyclic moiety showing exceptionally broad and important applications as privileged structure in the discovery of biologically functional scaffolds, organic materials preparation, as directing group in transition-metal-catalyzed 
transformations and as key building block in the synthesis of numerous organic compounds [24-28]. The amazingly rapid and broad permeation of 1,2,3-triazoles to multidisciplinary areas can majorly be attributed to the occurrence of robust synthetic methods toward this heterocycle. The copper-catalyzed click [3 + 2] cycloaddition of azides and alkynes [29-32], for example, has served enormously to the advances in both the preparation and application of 1,2,3-triazoles. In addition, the discovery of other metal-catalyzed alkyne-azide cycloadditions (MAAC) providing 1,2,3-triazoles with diverse substitution patterns triggers the continuous development of these metal-catalyzed cycloaddition strategies [33-35]. Alongside the vast progress happened in MAAC-based 1,2,3-triazole synthesis, the past decade has witnessed the emergence of another powerful cycloaddition tool for the 1,2,3-triazole synthesis: the metal-free cycloaddition of azides with activated dipolarophiles. As synthetic tools being able to provide 1,2,3-triazoles using an organocatalyst or other non-metal catalysts, this method shows distinctive advantages in enabling the production of 1,2,3-triazoles free of any heavy metal contamination [36-38].

Generally, the cycloaddition of azides with activated dipolarophiles such as strained cyclic alkynes, enamines, enolates, electron-deficient olefins, ylides, iminium cations and alkyne anions, etc., have been identified as reliable approaches to access 1,2,3-triazole scaffolds with multiple substitution patterns [39-44]. In addition, the azide-free annulation has evolved also as another sustainable strategy for the synthesis of many 1,2,3-triazoles in the past decade [45-50]. More notably, besides occurring as active intermediate in the enamine-mediated cycloaddition for 1,2,3-triazole construction, enamines with good stability and easy availability such as enaminones have exhibited also conspicuously versatile application in the metal-free synthesis of divergent 1,2,3-triazoles by directly acting as starting materials [51-54]. In 2016, Dehaen and co-workers [55] reported the synthesis of $\mathrm{N}$-substituted 1,2,3triazoles via the reactions of organoazides and the in situ prepared $\mathrm{N}, \mathrm{N}$-dimethylenaminones by $150{ }^{\circ} \mathrm{C}$ microwave irradiation and subsequent heating in toluene at $100{ }^{\circ} \mathrm{C}$, providing an effective protocol of enaminone-based 1,2,3-triazole synthesis. Interestingly, our continuous adventure in enaminone-based organic transformations has led us to the discovery that the cycloaddition of $N, N$-dimethylenaminones and tosyl azide efficiently affords $\mathrm{NH}$-1,2,3-triazoles with water as the only medium, and not any catalyst or additive is required. Considering the featured functions of $\mathrm{NH}$-1,2,3-triazoles [56-61] as well as the urgent desire in finding more sustainable methods enabling 1,2,3-triazole synthesis, we report herein our results in the water-mediated, catalyst-free synthesis of $\mathrm{NH}-1,2,3$-triazoles through the cycloaddition of enaminone and sulfonyl azide with mild heating $\left(40{ }^{\circ} \mathrm{C}\right)$ and simple operation.

\section{Results and Discussion}

To start the work, the reaction of enaminone 1a and tosyl azide (2) was tentatively run in water by heating at $60{ }^{\circ} \mathrm{C}$ in the presence of $t$-BuONa, which provided $N H$-1,2,3-triazole product $3 \mathbf{a}$ with $52 \%$ yield together with $N, N$-dimethyl tosyl amide as byproduct (entry 1, Table 1). Varying the additive to AcOH didn't lead to an improved result (entry 2, Table 1). To our delight, the parallel entry without using any catalyst or additive afforded 3a with identically good yield (entry 3 , Table 1 ). With this encouraging result, we then carried out a systematic screen of the reaction parameters using water as the fixed reaction medium. First, a slight increase in the loading of tosyl azide was able to evidently enhance the yield of 3a (entries 4 and 5, Table 1). Furthermore, the examination on the impact of the reaction temperature led to the observation of an excellent product yield by running the reaction at $40^{\circ} \mathrm{C}$ (entries $6-8$, Table 1$)$. The variation on the volume of the water, on the other hand, gave no better reaction results (entries 9 and 10, Table 1). Finally, a control experiment employing EtOH as the reaction medium gave 3a with evidently lower yield than the equivalent reaction using water (entry 11, Table 1).

Table 1: Screen and optimization of the reaction conditions. ${ }^{a}$

aGeneral conditions: enaminone $1 \mathrm{a}(0.2 \mathrm{mmol})$, tosyl azide $(2$ $0.2 \mathrm{mmol}$ ), additive (1 equiv) were stirred for $20 \mathrm{~h}$ in water $(2.0 \mathrm{~mL})$. bYield of isolated product based on 1a. ${ }^{\mathrm{c}} 0.3 \mathrm{mmol} 2 .{ }^{\mathrm{d}} 0.24 \mathrm{mmol} 2$. ${ }^{e} \mathrm{H}_{2} \mathrm{O}(3 \mathrm{~mL})$ was used. ${ }^{\mathrm{f}} \mathrm{H}_{2} \mathrm{O}(1 \mathrm{~mL})$ was used. ${ }^{\mathrm{g}} \mathrm{EtOH}$ was used as alternative reaction medium.

To examine the scope of this water-mediated 1,2,3-triazole synthesis, a broad range of enaminones 1 was then employed to react with tosyl azide under the optimal conditions. According to the acquired results (Figure 1), satisfactory tolerance of this water-mediated, catalyst-free protocol was verified by the 


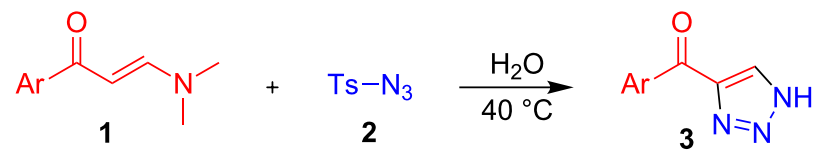<smiles>O=C(c1ccccc1)c1c[nH]nn1</smiles>

3a, $89 \%$<smiles>O=C(c1ccc(Br)cc1)c1c[nH]nn1</smiles>

3e, $72 \%$<smiles>O=C(c1ccc2ccccc2c1)c1c[nH]nn1</smiles>

$3 \mathbf{i}, 72 \%$<smiles>O=C(c1cccc([N+](=O)[O-])c1)c1c[nH]nn1</smiles>

$3 \mathrm{~m}, 70 \%$<smiles>O=C(c1ccc2c(c1)OCO2)c1c[nH]nn1</smiles>

3q, $70 \%$<smiles>CC(=O)c1c[nH]nn1</smiles>

$3 u, 0 \%$<smiles>Cc1ccc(C(=O)c2c[nH]nn2)cc1</smiles>

3b, $85 \%$<smiles>O=C(c1ccc([N+](=O)[O-])cc1)c1c[nH]nn1</smiles>

3f, $85 \%$<smiles>O=C(c1c[nH]nn1)c1cccc2ccccc12</smiles>

$3 \mathbf{j}, 57 \%$<smiles>Cc1ccccc1C(=O)c1c[nH]nn1</smiles>

3n, $75 \%$<smiles>O=C(c1ccc(Cl)c(Cl)c1)c1c[nH]nn1</smiles>

$3 r, 58 \%$<smiles>O=[N+]([O-])c1c[nH]nn1</smiles>

$3 v, 0 \%$<smiles>COc1ccc(C(=O)c2c[nH]nn2)cc1</smiles>

3c, $84 \%$<smiles>O=C(c1ccc(C(F)(F)F)cc1)c1c[nH]nn1</smiles>

3g, $96 \%$<smiles>COc1cccc(C(=O)c2c[nH]nn2)c1</smiles>

3k, $75 \%$<smiles>O=C(c1c[nH]nn1)c1ccccc1[N+](=O)[O-]</smiles>

3o, $58 \%$<smiles>O=C(c1c[nH]nn1)c1ccco1</smiles>

3s, $80 \%$

NC<smiles>c1c[nH]nn1</smiles>

3w, $0 \%$<smiles>O=C(c1ccc(Cl)cc1)c1c[nH]nn1</smiles>

3d, $88 \%$<smiles>N#Cc1ccc(C(=O)c2c[nH]nn2)cc1</smiles>

3h, $64 \%$<smiles>O=C(c1cccc(Cl)c1)c1c[nH]nn1</smiles>

3I, $63 \%$<smiles>COc1ccc(C(=O)c2c[nH]nn2)cc1OC</smiles>

3p, $66 \%$<smiles>O=C(c1ccsc1)c1c[nH]nn1</smiles>

3t, $66 \%$<smiles>O=C(c1cccnc1)c1c[nH]nn1</smiles>

$3 x, 0 \%$

Figure 1: Scope of the water-mediated synthesis of 4-acyl- $\mathrm{NH}-1,2,3$-triazoles. General conditions: enaminone 1 ( $0.2 \mathrm{mmol})$, tosyl azide $2(0.3 \mathrm{mmol})$ and water $(2 \mathrm{~mL})$, stirred at $40^{\circ} \mathrm{C}$ for $20 \mathrm{~h}$ (yields of isolated products are based on 1 ).

smooth synthesis of the 4-acyl- $\mathrm{NH}-1,2,3$-triazoles 3a-t containing versatile substructures (Figure 1). Besides the successful reactions employing enaminones independently containing electron-withdrawing and donating groups in the phenyl ring $(\mathrm{H}$, alkyl, alkoxyl, halogen, $\mathrm{CF}_{3}$ and cyano, etc.), the substitution in ortho- (3n, 3o, Figure 1) and meta-position of the phenyl ring $(3 \mathbf{k}-\mathbf{m}$, Figure 1) were also readily compatible with the synthesis. More notably, those enaminones functionalized with disubstituted phenyls (3p-r, Table 2) as well as heteroaryl-based enaminones (3s and 3t, Figure 1) also participated in the reaction to provide the divergently functionalized $\mathrm{NH}-1,2,3$-triazoles. The products were generally furnished with good to excellent yield, and the variation of product yields was found to associate with both the electron property and the sites of the substituent in the aryl ring of $\mathbf{1}$. However, when methyl-functionalized enaminone, $N, N$-dimethyl nitroenaminone, $N, N$ dimethyl cyanoenaminone, or pyridine-3-yl-functionalized enaminone was individually utilized, the expected reaction did not take place ( $\mathbf{3} \mathbf{u}-\mathbf{x}$, Figure 1). Moreover, it is notable that no $\mathrm{N}$-sulfonyl-1,2,3-triazole was isolated from any of the above experiments, indicating the excellent chemoselectivity of the present synthetic method.

In order to illustrate the potential application of this authentically green synthetic method, a gram scale synthesis of product 3a was conducted starting from enaminone 1a and tosyl azide (2). As expected, this entry turned out to be highly efficient affording product 3a with excellent yield (Scheme 1). In addi- 


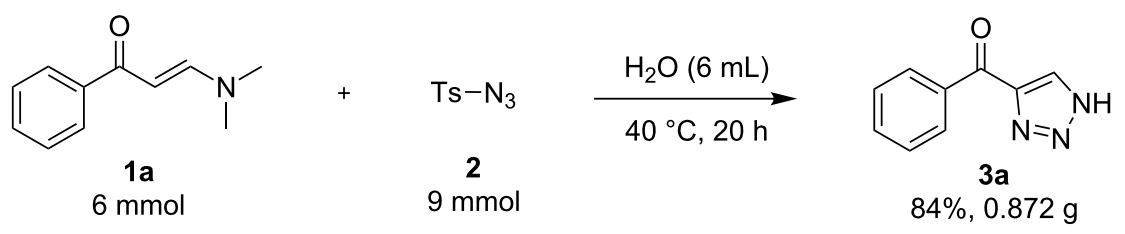

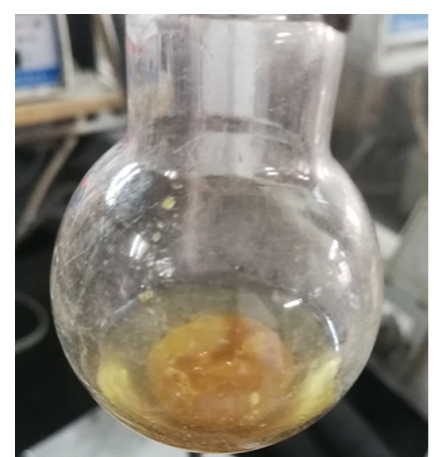

(a)

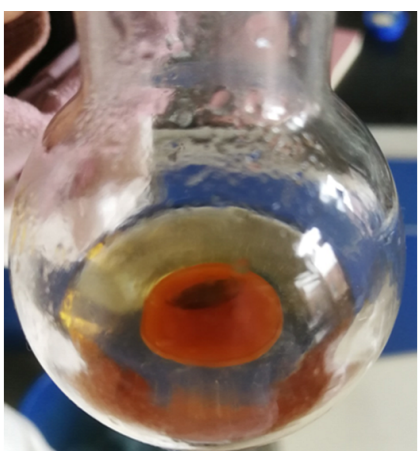

(b)

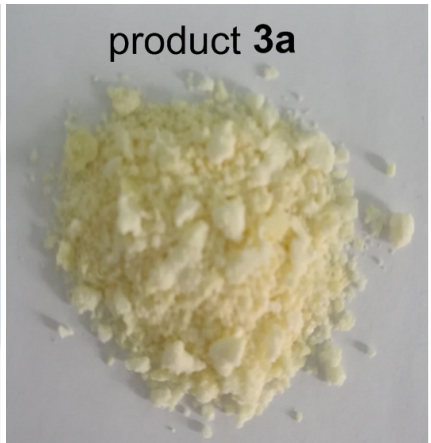

(c)

Scheme 1: The gram scale synthesis of 3a: (a) before reaction; (b) completed reaction; (c) the purified product 3a.

tion, the appearance of the reaction mixture before and after the reaction indicated the reaction as a heterogeneous "on water" process (Scheme 1).

Based on the known works employing organic solvents for similar synthesis and the present results [55], a possible mechanism for the reaction is proposed (Scheme 2). The reaction starts from the cycloaddition of enaminones $\mathbf{1}$ and tosyl azide (2) to provide 1,2,3-triazoline 4 which couples to water by strong hydrogen bond effect [51]. The presence of the hydrogen bonds may promote the elimination of the amino group and the acidic $\mathrm{C}-\mathrm{H}$ bond at the $\alpha$-position of the acyl group, which affords $N$-tosyl-1,2,3-triazole 5. Under the present reaction conditions, the intermediate 5 can undergo aminolysis and/or hydrolysis to provide the target products 3 . The participation of water throughout the reaction also explains the high efficiency of the method using water as reaction medium.

\section{Conclusion}

In summary, by means of the cycloaddition reactions between tertiary enaminones and tosyl azide employing water the sole reaction medium, a series of 4-acyl- $\mathrm{NH}$-1,2,3-triazoles has been

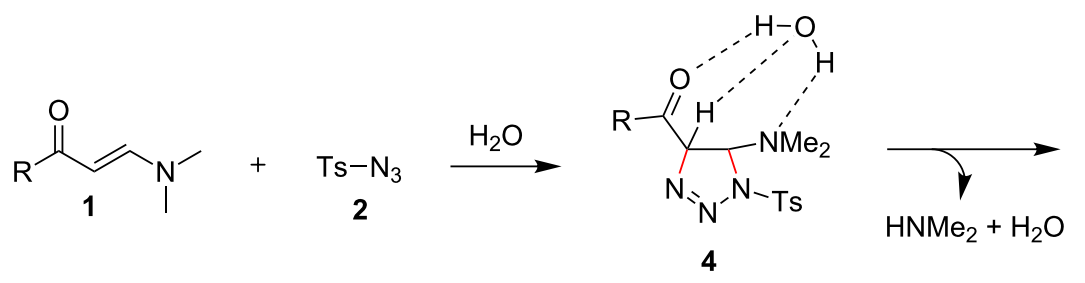<smiles>[R]C(=O)c1cn([I-])nn1</smiles>

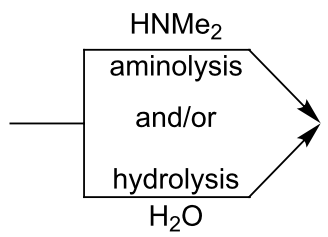<smiles></smiles>

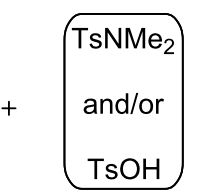


efficiently synthesized under catalyst-free and very mild heating conditions, thus providing the first water-mediated metal-free method toward the synthesis of 4-acyl- $\mathrm{NH}$-1,2,3-triazoles. The present method benefits from unique sustainability not only due to the metal/additive-free cycloaddition reaction, but also by applying the completely green reaction medium water and mild reaction temperature.

\section{Supporting Information}

\section{Supporting Information File 1}

General experimental information, experimental details of the synthesis of products $\mathbf{3}$, full characterization data as well as ${ }^{1} \mathrm{H} /{ }^{13} \mathrm{C}$ NMR spectra of all products. [https://www.beilstein-journals.org/bjoc/content/ supplementary/1860-5397-14-210-S1.pdf]

\section{Acknowledgements}

This work is financially supported by the National Natural Science Foundation of China (no. 21562025), Natural Science Foundation of Jiangxi Province (20161ACB21010) and an Open Project of the Key Laboratory of Rheumatic Diseases of Traditional Chinese Medicine in Zhejiang Province.

\section{ORCID ${ }^{\circledR}$ iDs}

Jie-Ping Wan - https://orcid.org/0000-0002-9367-8384

\section{References}

1. Lipshutz, B. H.; Ghorai, S.; Cortes-Clerget, M. Chem. - Eur. J. 2018, 24, 6672. doi:10.1002/chem.201705499

2. Simon, M.-O.; Li, C.-J. Chem. Soc. Rev. 2012, 41, 1415. doi:10.1039/C1CS15222J

3. Anastas, P.; Eghbali, N. Chem. Soc. Rev. 2010, 39, 301. doi:10.1039/B918763B

4. Gawande, M. B.; Bonifácio, V. D. B.; Luque, R.; Branco, P. S.; Varma, R. S. Chem. Soc. Rev. 2013, 42, 5522. doi:10.1039/c3cs60025d

5. Butler, R. N.; Goyne, A. G. Chem. Rev. 2010, 110, 6302. doi:10.1021/cr100162c

6. Chanda, A.; Fokin, V. V. Chem. Rev. 2009, 109, 725. doi:10.1021/cr800448q

7. Guo, W.; Wu, B.; Zhou, X.; Chen, P.; Wang, X.; Zhou, Y.-G.; Liu, Y.; Li, C. Angew. Chem., Int. Ed. 2015, 54, 4522. doi:10.1002/anie.201409894

8. Li, Y.; Huang, Y.; Gui, Y.; Sun, J.; Li, J.; Zha, Z.; Wang, Z. Org. Lett. 2017, 19, 6416. doi:10.1021/acs.orglett.7b03299

9. Zhang, F.-Z.; Tian, Y.; Li, G.-X.; Qu, J. J. Org. Chem. 2015, 80, 1107. doi:10.1021/jo502636d

10. Álvarez, M.; Gava, R.; Rodríguez, M. R.; Rull, S. G.; Pérez, P. J. ACS Catal. 2017, 7, 3707. doi:10.1021/acscatal.6b03669

11. Zhang, N.; Yang, D.; Wei, W.; Yuan, L.; Nie, F.; Tian, L.; Wang, H. J. Org. Chem. 2015, 80, 3258. doi:10.1021/jo502642n

12. Xie, L.-Y.; Li, Y.-J.; Qu, J.; Duan, Y.; Hu, J.; Liu, K.-J.; Cao, Z.; He, W.-M. Green Chem. 2017, 19, 5642. doi:10.1039/C7GC02304A
13. Xiao, F.; Chen, S.; Tian, J.; Huang, H.; Liu, Y.; Deng, G.-J. Green Chem. 2016, 18, 1538. doi:10.1039/C5GC02292D

14. Liu, K.-J.; Fu, Y.-L.; Xie, L.-Y.; Wu, C.; He, W.-B.; Peng, S.; Wang, Z.; Bao, W.-H.; Cao, Z.; Xu, X.; He, W.-M. ACS Sustainable Chem. Eng. 2018, 6, 4916. doi:10.1021/acssuschemeng.7b04400

15. Wu, C.; Xin, X.; Fu, Z.-M.; Xie, L.-Y.; Liu, K.-J.; Wang, Z.; Li, W.; Yuan, Z.-H.; He, W.-M. Green Chem. 2017, 19, 1983. doi:10.1039/C7GC00283A

16. Li, W.; Yin, G.; Huang, L.; Xiao, Y.; Fu, Z.; Xin, X.; Liu, F.; Li, Z.; He, W. Green Chem. 2016, 18, 4879. doi:10.1039/C6GC01196A

17. Tang, L.; Yang, Y.; Wen, L.; Yang, X.; Wang, Z. Green Chem. 2016, 18, 1224. doi:10.1039/C5GC02755A

18. Lin, Y.-m.; Lu, G.-p.; Wang, G.-x.; Yi, W.-b. J. Org. Chem. 2017, 82, 382. doi:10.1021/acs.joc.6b02459

19. Köhling, S.; Exner, M. P.; Nojoumi, S.; Schiller, J.; Budisa, N.; Rademann, J. Angew. Chem., Int. Ed. 2016, 55, 15510. doi:10.1002/anie.201607228

20. Chen, D.; Feng, Q.; Yang, Y.; Cai, X.-M.; Wang, F.; Huang, S. Chem. Sci. 2017, 8, 1601. doi:10.1039/C6SC04504A

21. Yang, J.; Mei, F.; Fu, S.; Gu, Y. Green Chem. 2018, 20, 1367. doi:10.1039/C7GC03644B

22. Liu, J.; Lei, M.; Hu, L. Green Chem. 2012, 14, 2534. doi:10.1039/c2gc35745c

23. Reddy, G. T.; Kumar, G.; Reddy, N. C. G. Adv. Synth. Catal. 2018, 360, 995. doi:10.1002/adsc.201701063

24. Kolb, H. C.; Sharpless, K. B. Drug Discovery Today 2003, 8, 1128. doi:10.1016/S1359-6446(03)02933-7

25. Nandivada, H.; Jiang, X.; Lahann, J. Adv. Mater. 2007, 19, 2197. doi:10.1002/adma.200602739

26. Thirumurugan, P.; Matosiuk, D.; Jozwiak, K. Chem. Rev. 2013, 113, 4905. doi:10.1021/cr200409f

27. Chen, Z.; Liu, Z.; Gao, G.; Li, H.; Ren, H. Adv. Synth. Catal. 2017, 359, 202. doi:10.1002/adsc.201600918

28. Xie, L.-Y.; Qu, J.; Peng, S.; Liu, K.-J.; Wang, Z.; Ding, M.-H.; Wang, Y.; Cao, Z.; He, W.-M. Green Chem. 2018, 20, 760. doi:10.1039/C7GC03106H

29. Huisgen, R. Angew. Chem., Int. Ed. Engl. 1963, 2, 565. doi:10.1002/anie.196305651

30. Kolb, H. C.; Finn, M. G.; Sharpless, K. B. Angew. Chem., Int. Ed. 2001, 40, 2004

doi:10.1002/1521-3773(20010601)40:11<2004::AID-ANIE2004>3.0.CO ;2-5

31. Tornøe, C. W.; Christensen, C.; Meldal, M. J. Org. Chem. 2002, 67, 3057. doi:10.1021/jo011148j

32. Hein, J. E.; Fokin, V. V. Chem. Soc. Rev. 2010, 39, 1302. doi:10.1039/b904091a

33. Zhang, L.; Chen, X.; Xue, P.; Sun, H. H. Y.; Williams, I. D.; Sharpless, K. B.; Fokin, V. V.; Jia, G. J. Am. Chem. Soc. 2005, 127, 15998. doi:10.1021/ja054114s

34. Destito, P.; Couceiro, J. R.; Faustino, H.; López, F.; Mascareñas, J. L. Angew. Chem., Int. Ed. 2017, 56, 10766. doi:10.1002/anie.201705006

35. Johansson, J. R.; Lincoln, P.; Nordén, B.; Kann, N. J. Org. Chem. 2011, 76, 2355. doi:10.1021/jo200134a

36. Ramasastry, S. S. V. Angew. Chem., Int. Ed. 2014, 53, 14310. doi:10.1002/anie.201409410

37. Lima, C. G. S.; Ali, A.; van Berkel, S. S.; Westermann, B.; Paixão, M. W. Chem. Commun. 2015, 51, 10784. doi:10.1039/C5CC04114G

38. Thomas, J.; Jana, S.; John, J.; Liekens, S.; Dehaen, W. Chem. Commun. 2016, 52, 2885. doi:10.1039/C5CC08347H 
39. Ramachary, D. B.; Shashank, A. B.; Karthik, S. Angew. Chem., Int. Ed. 2014, 53, 10420. doi:10.1002/anie.201406721

40. Li, W.; Wang, J. Angew. Chem., Int. Ed. 2014, 53, 14186. doi:10.1002/anie.201408265

41. Agard, N. J.; Preschner, J. A.; Bertozzi, C. R. J. Am. Chem. Soc. 2004, 126, 15046. doi:10.1021/ja044996f

42. Ramachary, D. B.; Ramakumar, K.; Narayana, V. V. Chem. - Eur. J. 2008, 14, 9143. doi:10.1002/chem.200801325

43. Belkheira, M.; Abed, D. E.; Pons, J.-M.; Bressy, C. Chem. - Eur. J. 2011, 17, 12917. doi:10.1002/chem.201102046

44. Kwok, S. W.; Fotsing, J. R.; Fraser, R. J.; Rodionov, V. O.; Fokin, V. V. Org. Lett. 2010, 12, 4217. doi:10.1021/ol101568d

45. Wan, J.-P.; Hu, D.; Liu, Y.; Sheng, S. ChemCatChem 2015, 7, 901. doi:10.1002/cctc.201500001

46. Chen, Z.; Cao, G.; Song, J.; Ren, H. Chin. J. Chem. 2017, 35, 1797. doi:10.1002/cjoc.201700459

47. van Berkel, S. S.; Brauch, S.; Gabriel, L.; Henze, M.; Stark, S.; Vasilev, D.; Wessjohann, L. A.; Abbas, M.; Westermann, B. Angew. Chem., Int. Ed. 2012, 51, 5343. doi:10.1002/anie.201108850

48. Chen, Z.; Yan, Q.; Liu, Z.; Zhang, Y. Chem. - Eur. J. 2014, 20, 17635. doi:10.1002/chem.201405057

49. Cai, Z.-J.; Lu, X.-M.; Zi, Y.; Yang, C.; Shen, L.-J.; Li, J.; Wang, S.-Y.; Ji, S.-J. Org. Lett. 2014, 16, 5108. doi:10.1021/ol502431b

50. Wan, J.-P.; Cao, S.; Liu, Y. J. Org. Chem. 2015, 80, 9028. doi:10.1021/acs.joc.5b01121

51. Bakulev, V. A.; Beryozkina, T.; Thomas, J.; Dehaen, W. Eur. J. Org. Chem. 2018, 262. doi:10.1002/ejoc.201701031 and references cited therein.

52. Cheng, G.; Zeng, X.; Shen, J.; Wang, X.; Cui, X. Angew. Chem., Int. Ed. 2013, 52, 13265. doi:10.1002/anie.201307499

53. Wan, J.-P.; Cao, S.; Liu, Y. Org. Lett. 2016, 18, 6034. doi:10.1021/acs.orglett.6b02975

54. Efimov, I.; Bakulev, V.; Beliaev, N.; Beryozkina, T.; Knippschild, U.; Leban, J.; Zhi-Jin, F.; Eltsov, O.; Slepukhin, P.; Ezhikova, M.; Dehaen, W. Eur. J. Org. Chem. 2014, 3684. doi:10.1002/ejoc.201402130

55. Thomas, J.; Goyvaerts, V.; Liekens, S.; Dehaen, W. Chem. - Eur. J. 2016, 22, 9966. doi:10.1002/chem.201601928

56. Thomas, J.; Jana, S.; Liekens, S.; Dehaen, W. Chem. Commun. 2016, 52, 9236. doi:10.1039/C6CC03744E

57. Cohrt, A. E.; Jensen, J. F.; Nielsen, T. E. Org. Lett. 2010, 12, 5414. doi:10.1021/ol102209p

58. Hu, Q.; Liu, Y.; Deng, X.; Li, Y.; Chen, Y. Adv. Synth. Catal. 2016, 358, 1689. doi:10.1002/adsc.201600098

59. Qvortrup, K.; Nielsen, T. E. Chem. Commun. 2011, 47, 3278. doi:10.1039/c0cc05274d

60. Deng, X.; Lei, X.; Nie, G.; Jia, L.; Li, Y.; Chen, Y. J. Org. Chem. 2017, 82, 6163. doi:10.1021/acs.joc.7b00752

61. Bakulev, V. A.; Beryozkina, T. A. Chem. Heterocycl. Compd. 2016, 52 , 4. doi:10.1007/s10593-016-1821-y

\section{License and Terms}

This is an Open Access article under the terms of the Creative Commons Attribution License

(http://creativecommons.org/licenses/by/4.0). Please note that the reuse, redistribution and reproduction in particular requires that the authors and source are credited.

The license is subject to the Beilstein Journal of Organic Chemistry terms and conditions:

(https://www.beilstein-journals.org/bjoc)

The definitive version of this article is the electronic one which can be found at:

doi:10.3762/bjoc. 14.210 